\title{
An Introduction to the Geometry of Stochastic Flows
}


This page is intentionally left blank 


\title{
An Introduction to the
} Geometry of

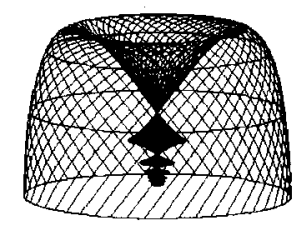

Stochastic Flows

\section{Fabrice Baudoin}

\author{
Université Paul Sabatier, France
}




\title{
Published by
}

Imperial College Press

57 Shelton Street

Covent Garden

London WC2H 9HE

Distributed by

World Scientific Publishing Co. Pte. Ltd.

5 Toh Tuck Link, Singapore 596224

USA office: 27 Warren Street, Suite 401-402, Hackensack, NJ 07601

UK office: 57 Shelton Street, Covent Garden, London WC2H 9HE

\section{British Library Cataloguing-in-Publication Data}

A catalogue record for this book is available from the British Library.

\begin{abstract}
AN INTRODUCTION TO THE GEOMETRY OF STOCHASTIC FLOWS
Copyright $(\mathcal{O} 2004$ by Imperial College Press

All rights reserved. This book, or parts thereof, may not be reproduced in any form or by any means, electronic or mechanical, including photocopying, recording or any information storage and retrieval system now known or to be invented, without written permission from the Publisher.
\end{abstract}

For photocopying of material in this volume, please pay a copying fee through the Copyright Clearance Center, Inc., 222 Rosewood Drive, Danvers, MA 01923, USA. In this case permission to photocopy is not required from the publisher.

ISBN $\quad 1-86094-481-7$ 
Au vent d'autan... 
This page is intentionally left blank 


\title{
Preface
}

The aim of the present text is to provide a self-contained introduction to the local geometry of the stochastic flows associated with stochastic differential equations.

The point of view we want to develop is that the local geometry of any stochastic flow is determined very precisely and explicitly by a universal formula referred to as the Chen-Strichartz formula. The natural geometry associated with the Chen-Strichartz formula is the sub-Riemannian geometry whose main tools are introduced throughout the text. By using the connection between stochastic flows and partial differential equations, we apply this point of view to the study of hypoelliptic operators written in Hörmander's form.

Many results contained in this text stem from my stay at the Technical University of Vienna where I had the great pleasure to discuss passionately with Josef Teichmann. I learnt a lot from him and I thank him very warmly. I also would like to take this opportunity to thank Nicolas Victoir for reading early drafts of various parts of the text and for his valuable suggestions.

\author{
F. Baudoin, \\ Toulouse, June 2004
}


This page is intentionally left blank 


\section{Contents}

Preface vii

1. Formal Stochastic Differential Equations 1

1.1 Motivation . . . . . . . . . . . . . . 1

1.2 The signature of a Brownian motion . . . . . . . . 3

1.3 The Chen-Strichartz development formula . . . . . . . 8

1.4 Expectation of the signature of a Brownian motion . . . . 14

1.5 Expectation of the signature of other processes . . . . 17

2. Stochastic Differential Equations and Carnot Groups 21

2.1 The commutative case . . . . . . . . . . . . . 22

2.2 Two-step nilpotent SDE's . . . . . . . . . . . . . 24

2.3 N-step nilpotent SDE's . . . . . . . . . . . . . . . 33

2.4 Pathwise approximation of solutions of SDEs . . . . . 45

2.5 An introduction to rough paths theory . . . . . . . 46

3. Hypoelliptic Flows 49

3.1 Hypoelliptic operators and Hörmander's theorem . . . . 50

3.2 Sub-Riemannian geometry . . . . . . . . . . . . 57

3.3 The tangent space to a hypoelliptic diffusion . . . . . . 60

3.4 Horizontal diffusions . . . . . . . . . . . . . 70

3.5 Regular sublaplacians on compact manifolds . . . . . . . 79

3.6 Stochastic differential equations driven by loops . . . . . . 85

$\begin{array}{lll}\text { Appendix A Basic Stochastic Calculus } & 97\end{array}$

A.1 Stochastic processes and Brownian motion . . . . . . . . 97 
A.2 Markov processes . . . . . . . . . . . . . . . . . 99

A.3 Martingales . . . . . . . . . . . . . . . 100

A.4 Stochastic integration . . . . . . . . . . 103

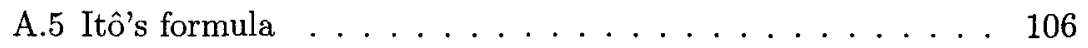

A.6 Girsanov's theorem . . . . . . . . . . . . . . . 106

A.7 Stochastic differential equations . . . . . . . . . . 108

A.8 Diffusions and partial differential equations . . . . . . 109

A.9 Stochastic flows . . . . . . . . . . . . . 110

A.10 Malliavin calculus . . . . . . . . . . . . . 111

A.11 Stochastic calculus on manifolds . . . . . . . . . 113

Appendix B Vector Fields, Lie Groups and Lie Algebras 117

B.1 Vector fields and exponential mapping . . . . . . . . 117

B.2 Lie derivative of tensor fields along vector fields . . . . . . 119

B.3 Exterior forms and exterior derivative . . . . . . . . 120

B.4 Lie groups and Lie algebras . . . . . . . . . . . . . . 121

B.5 The Baker-Campbell-Hausdorff formula . . . . . . . . 123

B.6 Nilpotent Lie groups . . . . . . . . . . . . . . . . 126

B.7 Free Lie algebras and Hall basis . . . . . . . . . . . . . . 126

B.8 Basic Riemannian geometry . . . . . . . . . . . . 127

$\begin{array}{ll}\text { Bibliography } & 133\end{array}$

$\begin{array}{ll}\text { Index } & 139\end{array}$ 